\section{INTRAVITAL MULTIPHOTON IMAGING OF INFILTRATING CD8 T CELL AND TUMOR CELL METABOLISM DURING IMMUNOTHERAPY IN A MURINE MELANOMA MODEL}

${ }^{1}$ Alexa Heaton*, ${ }^{2}$ Anna Hoefges, ${ }^{3}$ Peter Rehani, ${ }^{2}$ Angelica Lopez, ${ }^{2}$ Nathaniel Burkard ${ }^{2}$ Alexander Rakhmilevich, ${ }^{2}$ Amy Erbe, ${ }^{2}$ Paul Sondel, ${ }^{1}$ Melissa Skala. ${ }^{1}$ Morgridge Institute for Research and University of Wisconsin, Madison, WI, USA; ${ }^{2}$ University of Wisconsin, Madison, WI, USA; ${ }^{3}$ Morgridge Institute for Research, Madison, WI, USA

Background Intravital multiphoton microscopy (IMM) provides single cell imaging within intact living systems. IMM of the autofluorescent metabolic co-enzymes $\mathrm{NAD}(\mathrm{P}) \mathrm{H}$ and $\mathrm{FAD}$, optical metabolic imaging (OMI), provides in vivo label-free imaging of metabolic changes. The metabolism of tumor and immune cells is closely associated with cancer progression and tissue site, ${ }^{1-4}$ so we aim to study metabolic trends during administration of an effective, triple-combination immunotherapy within murine melanoma tumors. ${ }^{5}$ This therapy includes external beam radiation, intratumoral hu14.18-IL2 immunocytokine (anti-GD2 mAb fused to IL2), and intraperitoneal antiCTLA-4 leading to in situ vaccination and cure of GD2+ murine tumors. ${ }^{5}$ Previous work has shown that a $\mathrm{T}$ cell response is critical to the efficacy of this therapy, ${ }^{5-6}$ so we created an mCherry-labeled $\mathrm{T}$ cell mouse model to study this response. Here, IMM was used to image concurrent tumor and $\mathrm{CD} 8+\mathrm{T}$ cell metabolic trends during administration of immunotherapy.

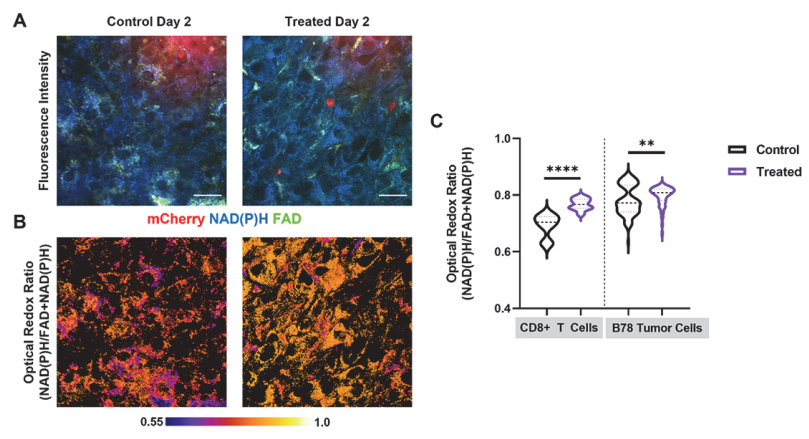

Abstract 43 Figure 1 In vivo multiphoton images of immune and tumor cell populations during immunotherapy. A) Representative in vivo fluorescence intensity images of B78 melanoma tumors growing in control and treated CD8 mCherry reporter mice show mCherry-labeled CD8+ T cells (red) infiltrating tumor tissue as well as autofluorescent metabolic coenzymes NAD(P)H (blue) and FAD (green) expressed by the tumor and T cells. Scale bar $25 \mu \mathrm{m}$. B) Corresponding in vivo optical redox ratio intensity images show redox balance within the tumor microenvironment. Treated tumors exhibit an increased optical redox ratio which may indicate increased glycolytic activity during immunotherapy. C) Quantified single-cell B78 tumor $(n=353)$ and CD8 T cell $(n=18)$ autofluorescence data. Both CD8 T cells $(p<0.0001)$ and tumor cells $(p<0.0034)$ exhibit significantly increased optical redox ratio with treatment $(n=2$ mice, median - center bold dashed line, 3rd quartile - upper dashed line, 1st quartile - lower dashed line, MannWhitney U Test).

Methods We created an mCherry-labeled CD8 + T cell mouse model through CRISPR/Cas9 knock-in. We then implanted syngeneic B78 (GD2+) melanoma cells into the flanks of these reporter mice to induce measurable tumors. Mice were anesthetized, skin flap surgery performed, and tumors imaged at several time points. IMM was performed using 750-1040 $\mathrm{nm}$ to excite $\mathrm{NAD}(\mathrm{P}) \mathrm{H}, \mathrm{FAD}$, and mCherry through a $40 \mathrm{X}$ (1.15 NA) objective. Fluorescence lifetime data was collected using time correlated single photon counting electronics. Murine tissues were harvested and analyzed via flow cytometry and multiplex immunofluorescence to corroborate IMM findings and characterize the immune infiltrate.

Results Here we demonstrate the feasibility of our IMM platform to capture single cell metabolic changes during immunotherapy administration. Through our intravital imaging we show that CD8 $\mathrm{T}$ cell and tumor cell redox ratio (intensity of $\mathrm{NAD}(\mathrm{P}) \mathrm{H} /$ intensity of $\mathrm{NAD}(\mathrm{P}) \mathrm{H}+\mathrm{FAD})$ is significantly increased in treated compared to control mice (figure 1), possibly indicating increased glycolytic activity. We also show differences in protein binding within both CD8 $\mathrm{T}$ cells and tumor cells during treatment. Overall, this technology enables analysis of metabolic changes in CD8 T cells and tumor cells in vivo during administration of our immunotherapy regimen. Conclusions These results provide additional support that the combination of intravital imaging with OMI allows for concurrent imaging of $\mathrm{T}$ cell infiltration and metabolic trends. Specifically, OMI enabled us to probe single cell metabolic changes occurring during our immunotherapy regimen. With continued work, this imaging platform may be leveraged to develop new combinations of immunotherapies.

Acknowledgements This work is supported by the Morgridge Institute for Research (Interdisciplinary Fellowship awarded to A.R.H.) and the NIH (R01 CA205101 and R35 CA197078). The authors thank the University of Wisconsin Carbone Cancer Center (UWCCC) Support Grant P30 CA014520, the UWCCC Translational Research Initiatives in Pathology laboratory - supported by the UW Department of Pathology and Laboratory Medicine and the Office of The Director NIH (S10OD023526), the UWCCC Flow Cytometry Laboratory, and the Genome Editing and Animal Models Laboratory for core services. The authors also thank Tiffany M. Heaster for training and thoughtful discussions as well as Dan Pham for cell isolation help.

\section{REFERENCES}

1. Renner K, Singer K, Koehl GE, Geissler EK, Peter K, Siska P J, Kreutz M. Metabolic Hallmarks of Tumor and Immune Cells in the Tumor Microenvironment. Front Immunol 2017, 8 Mar: 1-11.

2. Mockler MB, Conroy MJ, Lysaght J. Targeting T Cell Immunometabolism for Cancer Immunotherapy; Understanding the Impact of the Tumor Microenvironment. Front Oncol 2014, 4 May: 1-11.

3. Ghesquière B, Wong BW, Kuchnio A, Carmeliet P. Metabolism of stromal and immune cells in health and disease. Nature 2014; 511(7508):167-176.

4. Heaster TM, Heaton AR, Sondel PM, Skala MC. Intravital metabolic autofluores cence imaging captures macrophage heterogeneity across normal and cancerous tissue. Front Bioeng Biotechnol 2021, 9(April): 1-10.

5. Morris ZS, Guy El, Francis DM, Gressett MM, Werner LR, Carmichael LL, Yang RK, Armstrong EA, Huang S, Navid F, Gillies SD, Korman A, Hank JA, Rakhmilevich $A L$, Harari PM, Sondel PM. In situ tumor vaccination by combining local radiation and tumor-specific antibody or immunocytokine treatments. Cancer Res 2016; 76 (13): 3929-3941.

6. Morris ZS, Guy El, Werner LR, Carlson PM, Heinze CM, Kler JS, Busche SM Jaquish AA, Sriramaneni RN, Carmichael LL, Loibner H, Gillies SD, Korman AJ, Erbe AK, Hank JA, Rakhmilevich AL, Harari PM, Sondel PM. Tumor-specific inhibition of in situ vaccination by distant untreated tumor sites. Cancer Immunol Res 2018; 6(7): 825-834.

Ethics Approval All animal work was approved by the University of Wisconsin Institutional Animal Care and Use Committees.

http://dx.doi.org/10.1136/jitc-2021-SITC2021.043 